\title{
Characterization of cardiac autonomic function in COVID-19 using heart rate variability: a hospital based preliminary observational study
}

https://doi.org/10.1515/jbcpp-2020-0378

Received November 13, 2020; accepted February 18, 2021; published online March 12, 2021

\section{Abstract}

Objectives: The novel corona virus disease, which was initially reported in China in late 2019, has become a global pandemic affecting 330 million cases. COVID-19 affects predominantly the respiratory system, in addition to other organ systems, mainly the cardiovascular system. One of the hypotheses is that virus entering the target cells by binding to angiotensin converting enzyme 2 affecting hypothalamic pituitary axis could lead to dysautonomia which is measured by heart rate variability (HRV). HRV is a non-invasive measure of autonomic function that facilitates identification of COVID-19 patients at the risk of developing cardiovascular complications. So, we aimed to assess HRV in COVID patients and compare between COVID patients and normal controls.

Methods: In a case control design, we compared 63 COVID-19 infected patients with 43 healthy controls matched for age and gender. Along with clinical characterization, heart rate variability was evaluated using ambulatory 5 min ECG in lead II and expressed in frequency and time domain measures. Statistical analysis was performed using SPSS 17.0.

Results: Mean age of the study population was $49.1 \pm 14.2$ years and $71(66.9 \%)$ were males. Frequency domain measures high (HF) and low (LF) frequency powers were significantly decreased in COVID-19 patients compared to controls. HF/LF and LF/HF ratios were not different between groups. Time domain measures rMSSD (root mean

\footnotetext{
*Corresponding author: Deepalakshmi Kaliyaperumal, MD, Physiology, PSG Institute of Medical Sciences and Research, Peelamedu, Coimbatore, Tamil Nadu, 641004, India, E-mail: drdeepalakshmik@gmail.com Karthikeyan RK, Respiratory Medicine, PSG Institute of Medical Sciences and Research, Coimbatore, Tamil Nadu, India Murali Alagesan, Internal Medicine, PSG Institute of Medical Sciences and Research, Coimbatore, Tamil Nadu, India Sudha Ramalingam, Research and Innovation, PSG Institute of Medical Sciences and Research, Coimbatore, Tamil Nadu, India
}

square of successive RR interval differences) and SDNN (standard deviation of $\mathrm{NN}$ intervals) were significantly increased among COVID-19 subjects. COVID-19 infection was associated with increased parasympathetic activity as defined by rMSSD $>40$ adjusted odds ratio 7.609 (95\% CI 1.61-35.94); $\mathrm{p}=0.01$ \} and $\mathrm{SDNN}>60$ \{adjusted odds ratio 2.620 (95\% CI 1.070-6.44); $\mathrm{p}=0.035$ \} after adjusting for age, gender and comorbidities.

Conclusions: Our study results showed increased parasympathetic tone in COVID patients. Early diagnosis of autonomic imbalance in COVID patients is needed to plan management and limit progression of disease.

Keywords: heart failure; pulmonary hypertension; right heart.

\section{Introduction}

In December 2019, a novel coronavirus disease (nCoV) epidemic emerged in Wuhan City, Hubei Province, China. Owing to its high transmissibility and infectivity rate it spread across the world and WHO declared it as a pandemic on March 11, 2020 [1, 2]. As this virus predominantly affects the respiratory system it has been renamed as severe acute respiratory syndrome coronavirus 2 (SARS (oV-2) and the disease caused by this virus has been named as corona virus disease 19 (COVID-19) [3].

COVID-19 shows wide range of clinical presentations ranging from asymptomatic/mild symptoms (fever, cough, dyspnea, myalgia, fatigue, anosmia, dysgeusia and diarrhea) to severe illness like acute respiratory distress syndrome (ARDS), arterial and venous thrombosis, myocarditis and varieties of neurological manifestations [4-7]. A report from WHO says that " $80 \%$ of infections are mild or asymptomatic, $15 \%$ are severe infections and 5\% are critical infections" [8]. Co-morbid conditions like obesity, type 2 diabetes mellitus, coronary artery disease, chronic liver disease, chronic kidney disease and chronic respiratory disease are known to be risk factors for developing severe disease [9-11]. Wide spectrum of manifestations is explained by SARS CoV-2 having target cells in multiple organs and systems like respiratory tract including lung parenchyma, 
ileum, bladder, esophagus, heart, kidney, hypothalamus, pituitary, adrenal glands etc. These target cells have angiotensin converting enzyme-2 (ACE2) receptors in their cell wall. ACE2 binding affinity of the SARS CoV-2 spike protein ectodomain is one of possible mechanisms by which entry to these cells is facilitated [1, 12]. Histopathological and immune histochemical studies have clearly demonstrated a direct assault on these organs/systems by the SARS CoV-2 virus [13].

Though main portal of entry is respiratory system and hence the dominantly affected one, SARS CoV-2 reaches other systems through mechanism yet unknown. Neuroinvasive potential of SARS CoV-2 has been discussed in recent literature in the context of plausible explanation for variety of neurological manifestations of COVID-19 [14-16]. Earlier studies have demonstrated that SARS CoV-1 and MERS CoV (Middle east respiratory syndrome CoV) have the potential to enter and invade central nervous system, dominantly in brainstem structures [12, 17, 18]. Owing to the similarities in viral structure and receptor binding domain, neurotropism of SARS $\mathrm{CoV}-2$ can be speculated from the evidence found from SARS CoV-1. Though sparse, direct evidence of neurotropism of SARS CoV-2 is emerging in literature. A recent report by Paniz-Mondolfi et al. [19], demonstrated by electron microscopy, presence of viral particles in postmortem brain tissues of a COVID-19 patient. Another report by Moriguchi et al. [20], evidenced the presence of SARS CoV-2 in cerebrospinal fluid. It has been postulated that SARS CoV-2 can enter the central nervous system by several mechanisms such as invasion through olfactory epithelium [21], synapse-connected route from terminal nerve endings [22] and transmission across bloodbrain barrier by endothelial damage [19]. Clinical implications of neuropropensity of SARS CoV-2 range from mild symptoms like headache, dizziness etc., to severe manifestations like seizures, encephalitis, Guillain-Barre syndrome and cerebrovascular events. Involvement of autonomic nervous system (brainstem and hypothalamus) can lead to dysfunction of vital organs including cardiovascular system, thereby significantly influencing the outcome in COVID-19 patients. Cardiovascular system is also affected by the virus leading to manifestations like acute myocardial infarction, myocarditis and arterial \& venous thrombosis. Monitoring the cardiac autonomic function of patients with COVID-19 can help us identify the individuals who are at risk of developing adverse cardiovascular outcomes.

Autonomic dysfunction has been reported in viral infections like retrovirus (human immunodeficiency virus, human T-lymphotropic virus), herpes viruses, flavivirus, arbovirus, enterovirus 71 and lyssavirus [23]. Current literature on autonomic dysfunction in COVID-19 patients is very sparse, barring a few case reports [24, 25]. Though various other methods were employed in these clinical settings to elicit dysautonomia, heart rate variability (HRV) measurement was seldom used for this purpose. During last two decades, HRV is considered most objective, reproducible and validated tool for demonstration of autonomic dysfunction [26]. Frequency and time domain measures of HRV have emerged as the most promising markers of balance between parasympathetic and sympathetic activity of autonomic nervous system that controls homeostasis of all vital organs.

Eliciting an association between autonomic dysfunction and COVID-19 could clarify the genesis of many clinical manifestations and importantly the unpredictable natural course of the illness. In this study, we intended to evaluate for autonomic imbalance and the direction of its deviation in COVID-19 subjects by measuring HRV and comparing the differences in HRV metrics between SARS $\mathrm{CoV}-2$ positive and negative individuals.

\section{Methods}

This was an analytical cross-sectional study involving adult COVID-19 patients admitted for treatment in PSG Institute of Medical Sciences, Coimbatore, a specialized COVID-19 treating center in South India during March to June 2020. Sample frame during this period was approximately 500 inpatients whose COVID-19 status was confirmed by reverse transcription-polymerase chain reaction (RT-PCR) test of nasopharyngeal and oropharyngeal swab. Eligible inpatients (test group) of both genders, aged between 25 and 60 years were recruited from the sample frame by convenient sampling method. Patients with uncontrolled hypertension, coronary artery disease, cerebrovascular accident, family history of young myocardial infarction were excluded. Similarly, those patients on treatment with beta-blockers, inhaled or oral beta-mimetics, theophylline and other drugs with potential chronotropic effects were excluded. Patients with severe disease (those requiring oxygen support and/or intensive care) were also excluded. The comparison group included age and gendermatched healthy individuals from among the employees of medical school who tested negative for SARS CoV-2 by RT-PCR of their nasopharyngeal and oropharyngeal swab and fulfilled above mentioned selection criteria. This study was cleared by the institutional human ethics committee, and all study participants gave written informed consent. All such subjects recruited for the study underwent a detailed clinical examination.

\section{Assessment of HRV}

Study participants in both the groups were instructed to refrain from smoking, caffeine intake for $2 \mathrm{~h}$ and alcohol intake for $36 \mathrm{~h}$. They should have had adequate rest, at 
least $8 \mathrm{~h}$ of uninterrupted sleep on the night before the assessment of HRV and normal breakfast on the day of assessment. They were made to lie quietly in a couch in supine position for $5 \mathrm{~min}$ to alleviate the anxiety in a sound attenuated room with dim lighting and the temperature ranging from 20 to $25^{\circ} \mathrm{C}$.

After explaining the procedure to the subject, HRV, a quantitative marker of the autonomic activity was assessed using an ambulatory ECG system (INCO digital NIVIQURE, Bangalore, India) in lead II for $5 \mathrm{~min}$. It is a multichannel digital data acquisition system which enables to acquire, analyze and store ECG data. ECG data was obtained at a sampling rate of $1,024 \mathrm{~Hz}$ in standard lead II configuration. The interface RS232C-compatible module was used to transfer data from the recording unit to the computer. The transferred data was analyzed using inbuilt software system. The series of RR intervals obtained were subjected to frequency and time domain analysis. Time domain indices of HRV indicate the amount of variability in measurements of interbeat interval (IBI), which represent time period between successive heartbeats. Time domain measures include standard deviation of NN intervals (SDNN), root mean square of successive RR interval differences (rMSSD) and percentage of successive RR intervals (pNN50). Frequency domain measurements estimate the distribution of absolute or relative power into frequency bands. Frequency domain measures include low frequency (LF) and high frequency (HF) [26]. HF component indicates the parasympathetic activity, whereas LF represents both sympathetic and vagal activity, and SDNN, rMSSD and pNN50 measure parasympathetic activity [26, 27].

\section{Statistical analysis}

The data were examined initially for normality of distribution and homogeneity of variance and expressed in terms of mean \pm SD or percentage. Data with wide dispersion were expressed in log transformed values. Data from continuous variables were compared between study groups using Student's $t$-test whereas categorical variables were compared using Chi-Square test. Mann-Whitney $U$ test was performed for variables that were not normally distributed. HRV variables that were significantly different between the groups were used as dependent variables for logistic regression analysis. For this purpose, HRV measures were dichotomized to categorical variable (artificial categorization using median split [28]) using an arbitrary cut-off value that was close to the median as reported by Nunan et al. [27] in their systematic review of studies involving normal subjects. Stepwise logistic regression analysis was employed to identify significant covariates and to evaluate association between HRV measures and SARS CoV-2 status after adjusting for important confounders like age, gender and comorbidity. Subgroup analysis was performed to characterize clinical and HRV profiles of SARS CoV-2 infected subjects based on symptom status. A $p$ value of $<0.05$ was considered significant. All statistical analyses were carried out using SPSS version 17 software.

\section{Results}

In total, 106 participants were recruited for the study, which included 63 (59.4\%) COVID-19 subjects and 43 (40.6\%) healthy individuals who tested negative for SARS CoV-2. Among COVID-19 patients 33 (52.3\%) had mild to moderate symptoms and $30(47.6 \%)$ were asymptomatic. Mean age of the study population was $49.09 \pm 14.21$ years with $71(67 \%)$ male subjects and 35 (33\%) female subjects (Figure 1).

Comparing COVID-19 patients and healthy subjects, both groups were age and gender matched. Vital parameters like heart rate, $\mathrm{SPO}_{2}$ at room air, systolic and diastolic blood pressure showed no difference between the study groups. Among frequency domain HRV parameters, HF and LF powers were significantly decreased among COVID-19 patients as compared to healthy individuals. $\mathrm{HF} /$ LF ratio and LF/HF ratio were not different between the groups (Table 1). Among time domain parameters, mean rMSSD was significantly higher in the COVID-19 group compared to healthy individuals (Figure 2). Mean SDNN value was higher among COVID-19 subjects with a trend toward statistical significance.

In the above graphical representation, the box spans the interquartile range, ends of the box represent upper and lower quartiles, bold horizontal line within the box represents the median value and the whiskers show the

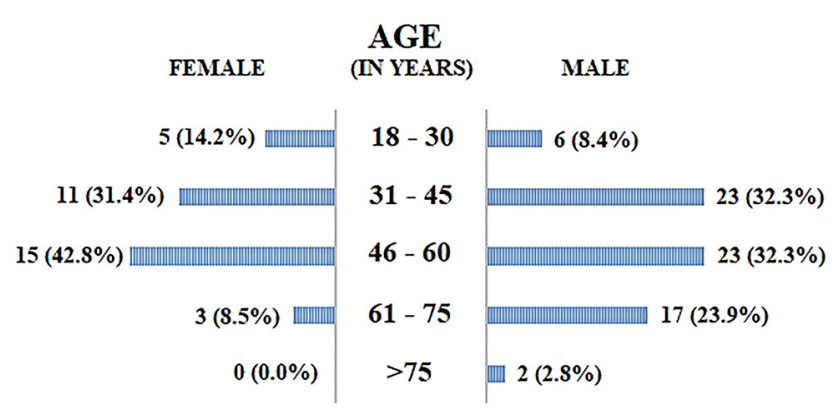

Figure 1: Age and gender distribution of study population. 
Table 1: Comparison of clinical profile and heart rate variability parameters between COVID-19 subjects and healthy individuals. Data shown as mean \pm SD and frequency $\{n(\%)\}$.

\begin{tabular}{|c|c|c|c|}
\hline Variables & $\begin{array}{r}\text { COVID-19 } \\
\text { subjects }(n=63)\end{array}$ & $\begin{array}{r}\text { Healthy } \\
\text { subjects }(n=43)\end{array}$ & p-Value \\
\hline Age, years & $48.39 \pm 16.3$ & $50.1 \pm 10.5$ & 0.517 \\
\hline Gender & & & 0.449 \\
\hline Male & $44(69.8 \%)$ & 27 (62.8\%) & \\
\hline Female & $19(30.2 \%)$ & $16(37.2 \%)$ & \\
\hline $\mathrm{SPO}_{2}$ in room air, $\%$ & $95 \pm 6$ & $97 \pm 1$ & 0.678 \\
\hline Systolic BP, mmHg & $124 \pm 15$ & $121 \pm 6$ & 0.386 \\
\hline Diastolic & $77 \pm 7$ & $77 \pm 4$ & 0.818 \\
\hline \multicolumn{4}{|l|}{$\mathrm{BP}, \mathrm{mmHg}$} \\
\hline $\mathrm{HR}$ & $84 \pm 15$ & $81 \pm 15$ & 0.151 \\
\hline $\mathrm{HF}^{\mathrm{a}}$ & $1.79 \pm 0.15$ & $2.09 \pm 0.39$ & $0.0001^{*}$ \\
\hline LF & $33.47 \pm 20.31$ & $77.46 \pm 50.8$ & $0.0001^{*}$ \\
\hline HF/LF ratio & $4.16 \pm 4.56$ & $2.34 \pm 1.89$ & 0.248 \\
\hline LF/HF ratio & $0.70 \pm 0.71$ & $0.64 \pm 0.35$ & 0.282 \\
\hline pNN50 & $4.45 \pm 8.12$ & $1.99 \pm 3.23$ & 0.561 \\
\hline $\mathrm{rMSSD}^{\mathrm{a}}$ & $1.49 \pm 0.58$ & $1.15 \pm 0.29$ & $0.019^{\star}$ \\
\hline $\mathrm{SDNN}^{\mathrm{a}}$ & $1.89 \pm 0.33$ & $1.73 \pm 0.10$ & 0.10 \\
\hline$r M S S D>40$ & $19(30.6 \%)$ & $2(4.7 \%)$ & $0.001^{b}$ \\
\hline SDNN $>60$ & $27(45.0 \%)$ & $11(25.6 \%)$ & $0.044^{b}$ \\
\hline
\end{tabular}

$\mathrm{SPO}_{2}$, oxygen saturation; $\mathrm{BP}$, blood pressure; $\mathrm{HR}$, heart rate; $\mathrm{SDNN}$, standard deviation of NN intervals; rMSSD, root mean square of successive RR interval differences; pNN50, percentage of successive RR intervals; LF, low frequency power; HF, high frequency power. *Mann-Whitney $U$ test, level of significance 0.05 . ${ }^{\text {a }}$ Log transformed values. ${ }^{\mathrm{b}} \mathrm{Chi}$ square test, level of significance 0.05 .

minimum and maximum values. The circles with numericals are outliers.

Based on the published data on range of observations and median value of normal subjects, we defined parasympathetic overtone when subjects had rMSSD more than
Table 2: Stepwise logistic regression analysis of association between COVID-19 infection and parasympathetic overtone as defined by $r M S S D>40$ or SDNN $>60$.

\begin{tabular}{lll}
\hline Parasympathetic overtone & Odds ratio $(95 \% \mathrm{Cl})$ & p-Value \\
\hline rMSSD>40 & & \\
$\begin{array}{l}\text { Unadjusted } \\
\text { Adjusted for age and gender }\end{array}$ & $9.058(1.98-41.35)$ & 0.004 \\
$\begin{array}{l}\text { Adjusted for age, gender and } \\
\text { diabetes mellitus type 2 }\end{array}$ & $8.174(1.75-38.22)$ & 0.008 \\
$\begin{array}{l}\text { Adjusted for age, gender and } \\
\text { presence of comorbidities }\end{array}$ & $7.609(1.61-35.94)$ & 0.01 \\
$\begin{array}{l}\text { SDNN>60 } \\
\text { Unadjusted }\end{array}$ & \\
$\begin{array}{l}\text { Adjusted for age and gender } \\
\text { Adjusted for age, gender and }\end{array}$ & $2.380(1.014-5.58)$ & 0.046 \\
$\begin{array}{l}\text { diabetes mellitus type 2 } \\
\text { Adjusted for age, gender and }\end{array}$ & $2.417(1.002-5.83)$ & 0.049 \\
presence of comorbidities & $2.620(1.070-6.44)$ & 0.035 \\
\hline
\end{tabular}

40 and SDNN more than 60 [27]. These dichotomous variables indicated that COVID-19 patients had higher parasympathetic overtone than the healthy subjects (Table 1). Stepwise logistic regression analysis revealed a significant association between SARS CoV-2 infection status and parasympathetic overtone after adjusting for age, gender, T2DM or the presence of one or more comorbidities (Table 2).

Subgroup analysis was performed comparing the characteristics between symptomatic and asymptomatic subjects with COVID-19 (Table 3). Symptomatic COVID-19 patients were elderly and predominantly males as compared to asymptomatic patients. Symptomatic patients more frequently had at least one co-morbidity. Common
A

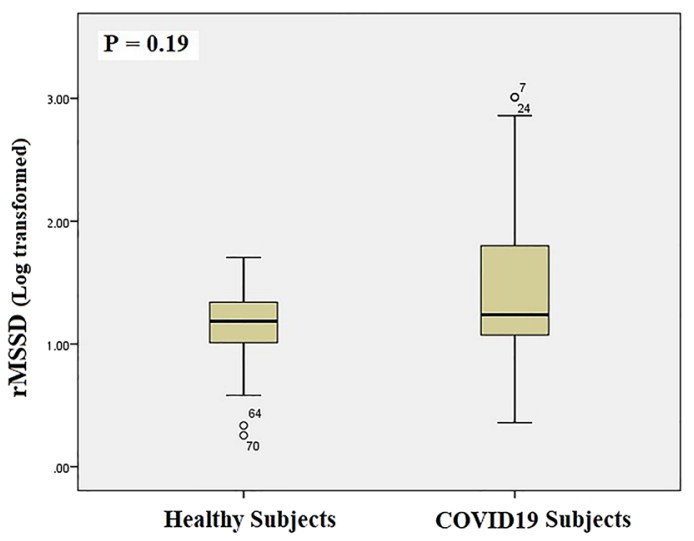

B

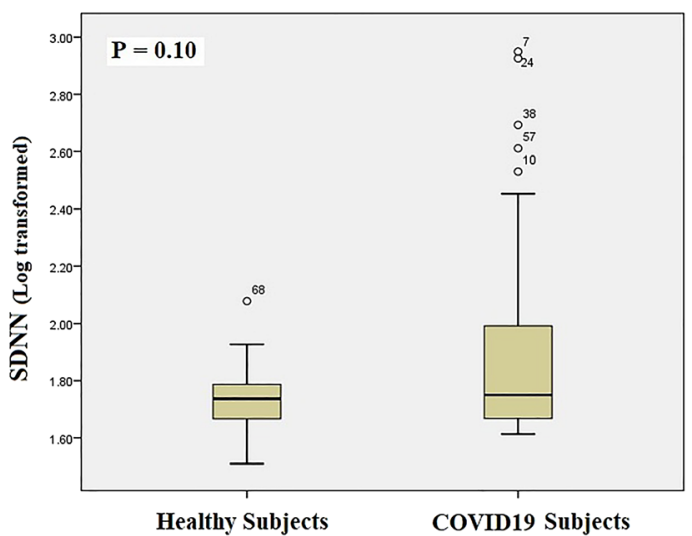

Figure 2: Boxplot graphical representation of rMSSD (A) and SDNN (B) among COVID-19 patients and healthy subjects. 
Table 3: Subgroup analysis of clinical profile and heart rate variability parameters among symptomatic and asymptomatic COVID-19 subjects. Data shown as mean \pm SD and frequency $\{n(\%)\}$.

\begin{tabular}{|c|c|c|c|}
\hline Variables & $\begin{array}{r}\text { Symptomatic } \\
\text { COVID-19 } \\
\text { subjects } \\
(n=33)\end{array}$ & $\begin{array}{r}\text { Asymptomatic } \\
\text { COVID-19 } \\
\text { subjects }(n=33)\end{array}$ & p-Value \\
\hline Age, years & $57.59 \pm 13.5$ & $38.57 \pm 13.1$ & $0.0001^{\mathrm{C}}$ \\
\hline Gender & & & $0.006^{\mathrm{b}}$ \\
\hline Males & 28 (84.8\%) & $16(53.3 \%)$ & \\
\hline Females & 5 (15.2\%) & 17 (46.7\%) & \\
\hline $\mathrm{SPO}_{2}$ in room air, \% & $94 \pm 9$ & $97 \pm 1$ & 0.072 \\
\hline Systolic BP, mmHg & $128 \pm 16$ & $121 \pm 15$ & 0.097 \\
\hline Diastolic BP, mmHg & $77 \pm 7$ & $77 \pm 8$ & 0.763 \\
\hline \multicolumn{4}{|l|}{ Comorbidities } \\
\hline DM type 2 & $11(36.7 \%)$ & 7 (23.3\%) & 0.260 \\
\hline Systemic hypertension & $10(33.3 \%)$ & $2(6.7 \%)$ & $0.010^{b}$ \\
\hline $\begin{array}{l}\text { Any one or more of } \\
\text { above comorbidities }\end{array}$ & $20(66.7 \%)$ & $8(26.7 \%)$ & $0.002^{b}$ \\
\hline $\mathrm{HR}$ & $88.14 \pm 17.11$ & $80.55 \pm 12.98$ & 0.055 \\
\hline $\mathrm{HF}$ & $64.61 \pm 21.22$ & $68.58 \pm 19.33$ & 0.442 \\
\hline LF & $35.38 \pm 21.22$ & $31.37 \pm 19.40$ & 0.437 \\
\hline $\mathrm{HF} / \mathrm{LF}$ ratio & $3.82 \pm 4.35$ & $4.54 \pm 4.83$ & 0.518 \\
\hline LF/HF ratio & $0.79 \pm 0.83$ & $0.61 \pm 0.55$ & 0.650 \\
\hline pNN50 & $4.58 \pm 8.73$ & $4.30 \pm 7.53$ & 0.358 \\
\hline $\mathrm{rMSSD}^{\mathrm{a}}$ & $1.41 \pm 0.62$ & $1.56 \pm 0.53$ & $0.086^{\star}$ \\
\hline SDNN $^{\mathrm{a}}$ & $1.87 \pm 0.36$ & $1.91 \pm 0.3$ & 0.135 \\
\hline
\end{tabular}

$\mathrm{SPO}_{2}$, oxygen saturation; $\mathrm{BP}$, blood pressure; $\mathrm{HR}$, heart rate; SDNN, standard deviation of NN intervals; rMSSD, root mean square of successive RR interval differences; pNN50, percentage of successive RR intervals; LF, low frequency power; HF, high frequency power.

*Mann-Whitney $U$ test, level of significance 0.05 . ${ }^{\text {'Log transformed }}$ values. ${ }^{\mathrm{b}} \mathrm{Chi}$ square test, level of significance 0.05 . 'Student's $t$-test, level of significance 0.05 .

co-morbidities among symptomatics were DM type 2 (36.7\%), Systemic hypertension (33.3\%), obesity $(10 \%)$, hypothyroidism (13.3\%) and psychomorbidity (10\%). Both frequency and time domain HRV parameters showed no difference between the subgroups.

\section{Discussion}

Our study clearly demonstrated an increased parasympathetic activity in COVID-19 patients, independent of important confounders like age, gender and comorbidities including diabetes mellitus. Autonomic dysfunction in COVID-19 subjects in our study was best demonstrated by time domain measures of HRV namely rMSSD and SDNN with predefined cut-off values. HF and LF powers in frequency domain were significantly decreased in COVID-19 subjects, though their ratios were not significantly different when compared to the healthy uninfected subjects. In a subgroup analysis of COVID-19 subjects, HRV measures were not different between asymptomatics and mild to moderate symptomatic. To our knowledge, our study was the first to demonstrate higher rate of autonomic imbalance among COVID-19 patients as compared to uninfected healthy group.

Our search through literature yielded scanty reports on autonomic dysfunction among COVID-19 patients. Ritwik Ghosh et al. [24] reported in one case of COVID-19, clinical features of autonomic dysfunction in the form of sinus arrhythmia, postural hypotension, intermittent profuse sweating, constipation, erectile dysfunction and squeezing sensation in the chest. Cardiac dysautonomia was not studied in this report. In another case report, Reiner Buchhorn et al. [25], studied a 58-year-old COVID-19 patient with $24 \mathrm{~h}$ ECG monitoring and found a significant decrease in heart rate and a paradoxical decline in HRV. But for these two case reports suggesting a possible autonomic dysfunction, no studies have yet, evaluated the presence of this important physiological disharmony in COVID-19 patients.

Though scanty in the context of COVID-19, plethora of evidence available in the literature demonstrating autonomic dysfunction in other infectious diseases like human immunodeficiency virus [29-31] human T Cell lymphotropic virus [32], Epstein Barr virus [33], cytomegalovirus [34], West Nile virus [35], Chagas disease [36, 37], diphtheria [38], leprosy [39], dengue[40], tetanus [41] and botulism [42]. Methodological differences in evaluating autonomic function as well as variations in study design do not allow head-to-head comparison of these studies with our findings in COVID-19 patients. In our search through literature, we found only two reports using HRV to link autonomic dysfunction with infection. Jeevagan Vijayabala et al. [43] postulated sympathetic dysfunction as one of the pathogenetic mechanisms in Dengue shock syndrome . Robert Carter et al. [40] examined HRV of 27 children during defervescence in dengue viral infection and found that cardiac parasympathetic activity was the major cause for reduction in heart rate during this period of illness. Their observations were mainly based on frequency domain measures of $\mathrm{HRV}$ after correcting for baseline changes in heart rate. Contradictory to the above observations, La-Orkhun et al. [44] found no significant changes in various time and frequency domain metrics of HRV at least $24 \mathrm{~h}$ after defervescence, and follow-up conducted at least 14 days after defervescence. Our findings are consistent with Jeevagan Vijayabala et al. and Robert Carter et al., that we too found an increased parasympathetic activity in COVID-19 patients as demonstrated by the increase in time domain variables of HRV. This study further substantiates 
two cases as cited above that reported autonomic dysfunction due to COVID-19. Proposed mechanisms of viral infection induced autonomic dysfunction include invasion of the central nervous system and the direct viral, toxin-mediated or immune-mediated involvement of the peripheral and autonomic nervous system [45].

Unlike the time domain variables, we found that frequency domains of HRV, specifically the LF/HF ratio were not different between the COVID-19 subjects and the healthy subjects. Traditionally LF/HF ratio was considered a marker of sympatho-vagal balance in cardiovascular system. However recent evidence this ratio merely indicates one part of complex non-linear interaction between sympathetic and parasympathetic nervous systems confounded by multiple physiological and mechanical factors [46]. Some of these confounders may have been missed in our study protocol. Also, smaller sample size may explain our inability to detect subtle difference in $\mathrm{LF} / \mathrm{HF}$ ratio between the groups.

Our study involved a standardized measurement of heart rate variability using an ambulatory 5 min ECG recording in lead II. Precision of our evaluation was further augmented by stringent selection of subjects and optimal conditions for HRV measurement during conduct of the study. Our study is limited by participation of only asymptomatics and mild to moderate symptomatic patients with SARS CoV-2 infection. Severely ill COVID-19 patients were excluded from the study because we believed that factors like stress, cytokine storm, drugs like steroids, vasopressors etc., positive pressure ventilation, prolonged hospitalization and related psychomorbidity that typically characterize these patients may have a confounding effect on our observations. None of our study subjects had any of these factors that could have possibly altered our findings. Sample size of the study was not adequate to provide enough statistical power to our findings. But we believe that this preliminary report can serve a stimulus for future research in this direction. A larger sample size could have facilitated further evaluation of association between symptoms and autonomic function in our subjects.

In conclusion, this study has found that COVID-19 is associated with autonomic dysfunction whose mechanism and prognostic implications need to be evaluated further. HRV measurement, being a simple, noninvasive, inexpensive tool, its utility in clinical practice as a possible rapid diagnostic and prognostic marker needs to be assessed in future research.

Research funding: None declared.

Author contributions: All authors have accepted responsibility for the entire content of this manuscript and approved its submission.
Competing interests: Authors state no conflict of interest. Informed consent: Informed consent was obtained from all individuals included in this study.

Ethical approval: This study was cleared by the local institutional human ethics committee and all study participants gave written informed consent.

\section{References}

1. Huang C, Wang Y, Li X, Ren L, Zhao J, Hu Y, et al. Clinical features of patients infected with 2019 novel coronavirus in Wuhan, China. Lancet 2020;395:497-506.

2. Wang C, Horby PW, Hayden FG, Gao GF. A novel coronavirus outbreak of global health concern. Lancet 2020;395:470-3.

3. Su S, Wong G, Shi W, Liu J, Lai ACK, Zhou J, et al. Epidemiology, genetic recombination, and pathogenesis of coronaviruses. Trends Microbiol 2016;24:490-502.

4. Gorbalenya AE, Baker SC, Baric RS, Groot RJ, Drosten C, Gulyaeva AA, et al. Severe acute respiratory syndrome-related coronavirus: the species and its viruses: a statement of the Coronavirus Study Group. Nat Microbiol 2020;5:536-44.

5. Wang D, Hu B, Hu C, Zhu F, Liu X, Zhang J, et al. Clinical characteristics of 138 hospitalized patients with 2019 novel corona virus-infected pneumonia in Wuhan, China. JAMA J Am Med Assoc 2020;323:1061-9.

6. Ellul MA, Benjamin L, Singh B, Lant S, Michael BD, Easton A, et al. Neurological associations of COVID-19. Lancet Neurol 2020;19: 767-83.

7. Vaira LA, Salzano G, Deiana G, De Riu G. Anosmia and Ageusia common findings in COVID-19 patients. Laryngoscope 2020;130: 1787.

8. Coronavirus disease 2019 (COVID-19) situation report. Available from: www.who.int>docs>20200306-sitrep-46-covid-19 [Accessed 11 Jan 2021].

9. Dong E, Du H, Gardner L. An interactive web-based dashboard to track COVID-19 in real time. Lancet Infect Dis 2020;3099:19-20.

10. Guan W, Ni Z, Hu Y. Clinical characteristics of coronavirus disease 2019 in China. N Engl J Med 2020;382:1708-20.

11. Zhang JJ, Dong X, Cao YY. Clinical characteristics of 140 patients infected by SARS-CoV-2 in Wuhan, China. Allergy 2020;75: 1730-41.

12. Zou X, Chen K, Zou J, Han P, Hao J, Han Z. Single-cell RNA-seq data analysis on the receptor ACE2 expression reveals the potential risk of different human organs vulnerable to 2019-nCoV infection. Front Med 2020;14:185-92.

13. Ding $Y$, He L, Zhang Q, Huang Z, Che X, Hou J, et al. Organ distribution of severe acute respiratory syndrome (SARS) associated coronavirus (SARS-CoV) in SARS patients: implications for pathogenesis and virus transmission pathways. J Pathol 2004;203:622-30.

14. Li YC, Bai WZ, Hashikawa T. The neuroinvasive potential of SARSCoV2 may play a role in the respiratory failure of COVID-19 patients. J Med Virol 2020:1-4. https://doi.org/10.1002/jmv. 25728.

15. Huang $P$, Tang L, Ren L, Liu L. Research progress in nervous system damage caused by SARS-CoV-2. Zhong Nan Da Xue Bao Yi Xue Ban 2020;28:1247-54. 
16. Yashavantha Rao HC, Jayabaskaran C. The emergence of a novel coronavirus (SARS-CoV-2) disease and their neuroinvasive propensity may affect in COVID 19 patients. J Med Virol 2020;92: 786-90.

17. Li K, Wohlford Lenane C, Perlman S, Zhao J, Jewell AK, Reznikov LR, et al. Middle East respiratory syndrome coronavirus causes multiple organ damage and lethal disease in mice transgenic for human dipeptidyl peptidase 4. J Infect Dis 2016;213: 712-22.

18. McCray PB Jr, Pewe L, Wohlford Lenane C, Hickey M, Manzel L, Shi L, et al. Lethal infection of K18-hACE2 mice infected with severe acute respiratory syndrome coronavirus. J Virol 2007;81: 813-21.

19. Paniz-Mondolfi A, Bryce C, Grimes Z, Gordon RE, Reidy J, Lednicky J, et al. Central nervous system involvement by severe acute respiratory syndrome coronavirus-2 (SARS-CoV-2). J Med Virol 2020;92:699-702.

20. Moriguchi T, Harii N, Goto J, Harada D, Sugawara H, Takamino J, et al. A first Case of Meningitis/Encephalitis associated with SARS-Coronavirus-2. Int J Infect Dis 2020.

21. Netland J, Meyerholz DK, Moore S, Cassell M, Perlman S. Severe acute respiratory syndrome coronavirus infection causes neuronal death in the absence of encephalitis in mice transgenic for human ACE2. J Virol 2008;82:7264-75.

22. Li YC, Bai WZ, Hirano N, Hayashida T, Taniguchi T, Sugita Y, et al. Neurotropic virus tracing suggests a membranous coating mediated mechanism for transsynaptic communication. J Comp Neurol 2013;521:203-12.

23. Carod-Artal FJ. Infectious diseases causing autonomic dysfunction. Clin Auton Res 2018;28:67-81.

24. Ghosh R, Roy D, Sengupta S, Benito-Leon J. Autonomic dysfunction heralding acute motor axonal neuropathy in COVID-19. J Neurovirol 2020;26:964-66.

25. Buchhorn R, Baumann C, Willaschek C. Heart rate variability in a patient with coronavirus disease 2019. Int Cardiovasc Forum J 2020. https://doi.org/10.17987/icfj.v20i0.685.

26. Task force of the European Society of Cardiology and the North American Society of Pacing and Electrophysiology. Heart rate variability: standards of measurement, physiological interpretation and clinical use. Circulation 1996;93:1043-65.

27. Nunan D, Sandercock GRH, Brodie DA. A quantitative systematic review of normal values for short-term heart rate variability in healthy adults. Pacing Clin Electrophysiol 2010; 33:1407-17.

28. De Coster J, Gallucci M, Anne-Marie R. Iselin. Best practices for median splits, artificial categorization and their continuous alternatives. J Exp Psychopathol 2011;2:197-209.

29. DM FS, Umekawa S, Kocher M, Kallianpur KJ, Shikuma CM, Low P. Symptoms of autonomic dysfunction in human immunodeficiency virus. Open Forum Infect Dis 2015;2:ofv103.

30. Mittal CM, Wig N, Mishra S, Deepak KK. Heart rate variability in human immunodeficiency virus-positive individuals. Int J Cardiol 2004;94:1-6.
31. Becker K, Gorlach I, Frieling T, Haussinger D. Characterization and natural course of cardiac autonomic nervous dysfunction in HIV-infected patients. AIDS 1997;11:751-7.

32. Alamy AH, Menezes FB, Leite AC, Nascimento OM, Araujo AQ. Dysautonomia in human T-cell lymphotrophic virus type I-associated myelopathy/tropical spastic paraparesis. Ann Neurol 2001;50:681-5.

33. Bennett JL, Mahalingam R, Wellish MC, Gilden DH. Epstein-Barr virus-associated acute autonomic neuropathy. Ann Neurol 1996; 40:453-5.

34. Nakao K, Namekawa M, Kondo S, Ono S, Nakano I. Subacute autonomic and sensory neuropathy closely related to cytomegalovirus infection preceded by frequent syncopal attacks. Rinsho Shinkeigaku 2016;8:555-9.

35. Bode AV, Sejvar JJ, Pape WJ, Campbell GL, Marfin AA. West Nile virus disease: a descriptive study of 228 patients hospitalized in a 4-county region of Colorado in 2003. Clin Infect Dis 2006;42: 1234-40.

36. Junqueira LF Jr. Insights into the clinical and functional significance of cardiac autonomic dysfunction in Chagas disease. Rev Soc Bras Med Trop 2012;45:243-52.

37. Vasconcelos DF, Junqueira LF Jr. Cardiac autonomic and ventricular mechanical functions in asymptomatic chronic chagasic cardiomyopathy. Arq Bras Cardiol 2012;98:111-9.

38. Illarramendi X, Buhrer-Sekula S, Sales AM, Bakker MI, Oliveira A, Nery JA, et al. High prevalence of vasomotor reflex impairment in newly diagnosed leprosy patients. Eur J Clin Invest 2005;35: 658-65.

39. Idiaquez J. Autonomic dysfunction in diphtheritic neuropathy. J Neurol Neurosurg Psychiatry 1992;55:159-61.

40. Carter R, III, Hinojosa-Laborde C, Convertino VA. Heart rate variability in patients being treated for dengue viral infection: new insights from mathematical correction of heart rate. Front Physiol 2014;5:46.

41. Lin TS, Chen LK, Lin TY, Wen SH, Chen MC, Jan RH, et al. Autonomic dysfunction because of severe tetanus in an unvaccinated child. PediatrNeonatol 2011;52:169-71.

42. Merz B, Bigalke H, Stoll G, Naumann M. Botulism type B presenting as pure autonomic dysfunction. Clin Auton Res 2003; 13:337-8.

43. Vijayabala J, Attapaththu M, Jayawardena P, De Silva SG, Constantine G. Sympathetic dysfunction as a cause for hypotension in dengue shock syndrome. Chin Med J 2012;125:3757-8.

44. La-Orkhun V, Supachokchaiwattana P, Lertsapcharoen $P$, Khongphatthanayothin A. Spectrum of cardiac rhythm abnormalities and heart rate variability during the convalescent stage of dengue virus infection: a Holter study. Ann Trop Paediatr 2011;31:123-8.

45. Billman GE. The LF/HF ratio does not accurately measure cardiac sympatho-vagal balance. Front Physiol 2013;4:26.

46. Wu Y, Xu X, Chen Z, Duan J, Hashimoto K, Yang L, et al. Nervous system involvement after infection with COVID-19 and other coronaviruses. Brain Behav Immun 2020;87:18-22. 